\title{
Fatigue Life Estimation of Kenaf Reinforced Composite Materials by Non-destructive Techniques
}

\author{
M. J. Suriani ${ }^{1, *}$, Aidy Ali ${ }^{2}$, A. Khalina ${ }^{3}$, S. M. Sapuan ${ }^{3}$, Haftirman ${ }^{4}$ \\ ${ }^{1}$ School of Ocean Engineering, University of Malaysia Terengganu, Malaysia \\ ${ }^{2}$ Faculty of Mechanical Engineering, National Defence University of Malaysia, Malaysia \\ ${ }^{3}$ Faculty of Engineering, University of Putra Malaysia, Malaysia \\ ${ }^{4}$ School of Mechatronic Engineering, University of Malaysia Perlis, Malaysia
}

Copyright $\mathrm{O} 2016$ by authors, all rights reserved. Authors agree that this article remains permanently open access under the terms of the Creative Commons Attribution License 4.0 International License

\begin{abstract}
In this study, fatigue life of natural fiber reinforced composite materials was predicted due to manufacturing defects fatigue damage modes. Kenaf bast fibers were used to fabricate natural fiber composite materials with epoxy as a binding material. The Kenaf fiber reinforced composites were manufactured using a hand lay-up process. The defects in Kenaf reinforced composite materials were determined by a non-destructive technique using Infrared (IR) thermal imager. The thermography analyses were verified by optical microscope and scanning electron microscope (SEM) investigations. Then, the Mathematical model for estimating fatigue life by IR thermal imaging technique based on damage accumulation model is proposed. This proposed model is named as S-IR thermal imaging fatigue life model. Determinations of fatigue damage has been predicted and it found that it damage has been fixed with the predicting results. S-IR model proposed that $60 \%$ kenaf epoxy with thickness $0.3 \mathrm{~cm}$ is recommended as the best formulation to fabricate the specimens due to a longer fatigue life recorded and the result obtained from the fatigue cyclic tension test shows that $60 \%$ kenaf epoxy with thickness $0.3 \mathrm{~cm}$ had the highest fatigue resistance as indicated by a highest range of stress level, 119.71-53.20 MPa.
\end{abstract}

Keywords Fatigue Life, Natural Fiber Reinforced Composite, Non-destructive Technique

\section{Introduction}

The reinforcement of natural fiber in polymer composites has attracted researcher, academicians and various industries [1], and there has been growing interest in the use of natural fibres as reinforcement in polymer matrix composite due many advantages of using natural fibres compared to synthetic fibre. Ku et al (2011), stated that natural fibres have many advantages compared to glass fibre, for example they have low density, recyclabe, biodegradable, renewable raw materials and have relatively high strength and stiffness [2]. In a literatures review, the gap of knowledge has been revealed .The applications of natural fibre such as Kenaf [3], pineapple leaf [4], sisal [5],jute [6] oil palm [7] and coir [8] as the reinforcement in the composite materials are trends by all researcher worldwide. Some of the applications in natural fibre reinforced composite materials involved components to cyclic loading. Cyclic loading will cause damage and material degradation in cummulative manner. Therefore study on a fatigue life prediction on natural fibres reinforced composite materials is essential and necessary to allow their applications where cyclic loads are experienced. Moreover, it is also an essential to have a non-destructive technique (NDT) tools to predict the performance of the structures and proved the results evidence of experimental work done on a composite materials in order to schedule the maintenance or replacement of component before its failure. NDT in engineering fields is not new but nowadays these applications become used widely. The properties of materials can determine by defects and damages modes and nowadays, NDT is frequently replacing destructive techniques in determining the properties of materials [9]. NDT provides information of product properties such as discontinuities and separations; structures; dimension and metrology, physical and mechanical properties, composition and chemical analysis, stress and dynamics response, signature analysis and abnormal sources of heat [10]. A study on modeling of fatigue life of composite materials by using thermal imaging technique should be carried out to explore a new research data and present a good understanding on using a NDT on fatigue failure in natural fiber reinforced composite materials. Thus, this study promotes the usage of thermal imaging namely Infrared (IR) technique to estimate the fatigue life of natural fibre reinforced composite materials whilst presenting ways to understand the use of non-destructive technique on fatigue failure. The results of this study are hoped to bridge and narrow down the gap exist within the body of knowledge of 
fatigue life in relation to natural fibre reinforced composite materials.

\section{Methods}

\subsection{Preparation of Materials}

In this study, the material used was a treated Kenaf bast fibre provided by the Institute of Tropical and Forest Product (INTROP), UPM, Serdang, Selangor, Malaysia. The raw Kenaf bast fibres were combed to disrupt and untangle the strong bonds between individual fibres. The Kenaf bast fibres were cut to a length of $25 \mathrm{~cm}$ using scissors. Epoxy with a density of $1.15 \mathrm{~g} / \mathrm{cm}^{3}$ was used as a binding material. Epoxies specimens were prepared in order to control and determine the optimum temperature and curing time for processing the Kenaf reinforced epoxy composite. The volume of epoxies used for the thickness of $0.3 \mathrm{~cm}$, $112.5 \mathrm{~cm}^{3}$ equal to $129.4 \mathrm{~g}$ based on the volume of the mould, in accordance with ASTM D3039.

\subsection{Determination of Defects and Fatigue Damage}

Infrared (IR) thermal imaging and investigation techniques have been used to detect the defects on the surface of Kenaf reinforced epoxy composites. This investigation and measurements were using active thermography. These experiments were carried on the emissivity of 0.92 and the room temperature is $29^{\circ} \mathrm{C}$ with the relative humidity of $70 \%$. Scanning electron microscopy (SEM) was then used to determine the defects in the Kenaf/epoxy composites and to verify the results obtained from IR thermal imaging and from the optical microscope.

\subsection{Tension Test}

There were two parts of evaluation and assessment done simultaneously namely fatigue tension-tension test and fatigue damage determination using IR thermal imaging technique. Fatigue tension-tension test was done at ASTM D 3479/ D 3479M-96 (2007) which is a Standard Test Method for Tension-Tension Fatigue of Polymer Matrix Composite Materials using INSTRON model 8871 machine.

\subsection{Predicting of Fatigue Life}

The results by the proposed model also were verified with the fatigue experimental results. Figure 1 shows the $S-I R$ fatigue life model.

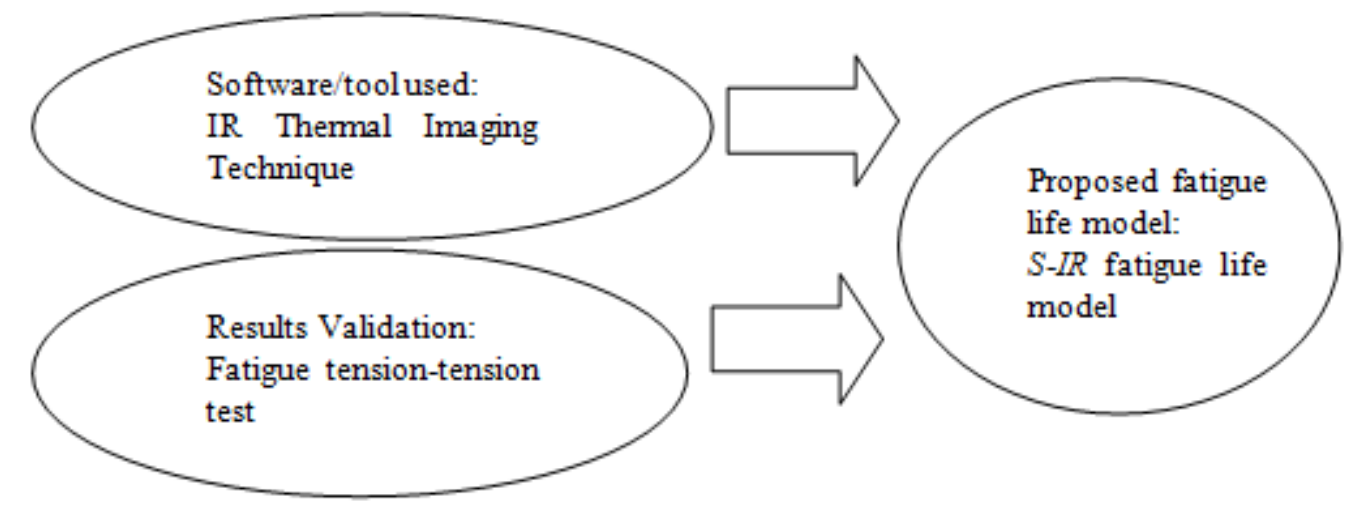

Figure 1. S-IR fatigue life model profile 


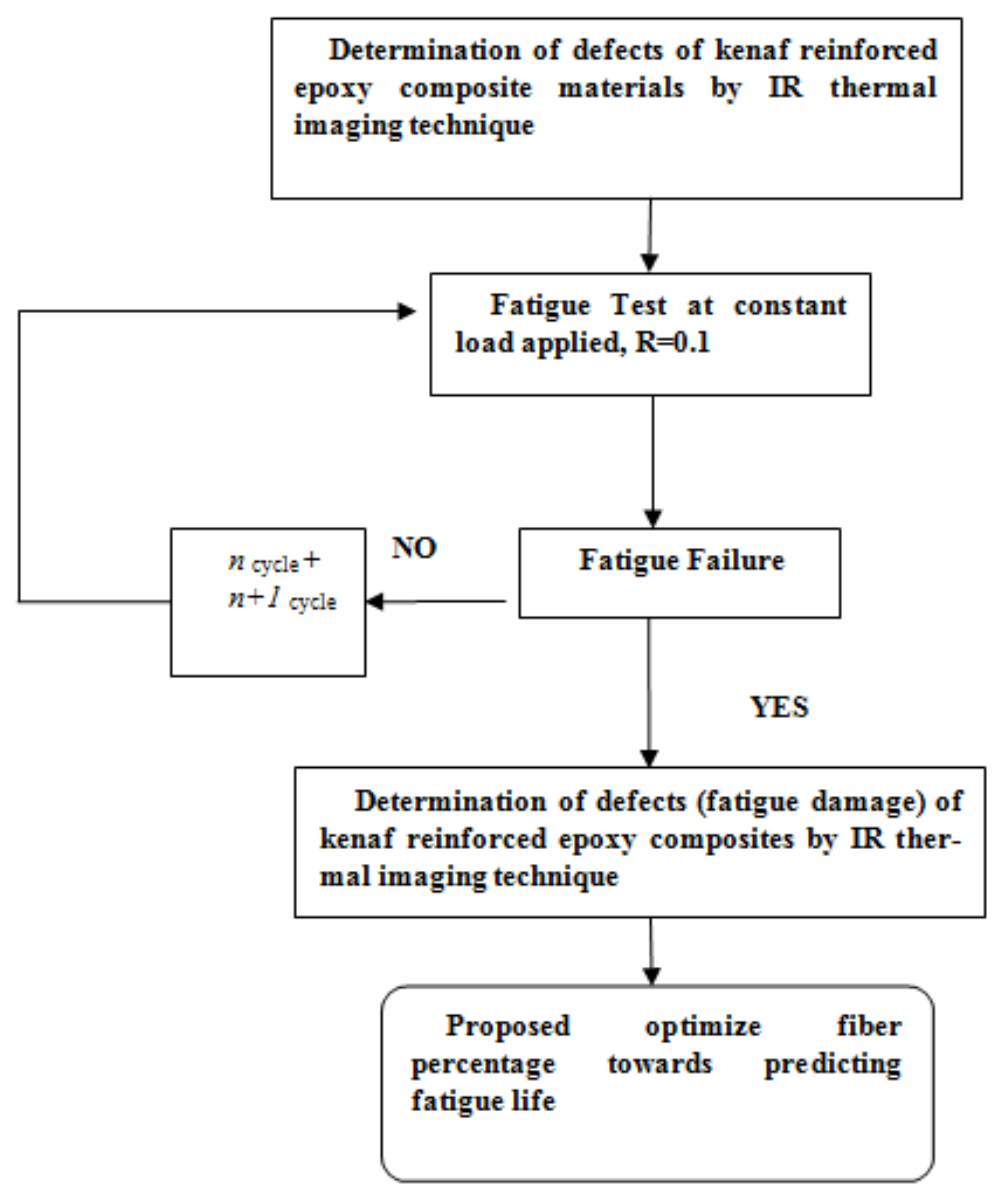

Figure 2. Flowchart of $S-I R$ fatigue life model

The flowchart of the proposed fatigue life model in kenaf reinforced epoxy composite materials is depicted in Figure 2 and explained in the following:

i) Determination size of defects of kenaf reinforced epoxy composite materials is determined using IR thermal imaging technique.

ii) Fatigue test at constant load and stress ratio, $R=0.1$

iii) Determination of fatigue damage (in terms of area of damages, $A_{d}$ at the highest temperature recorded) is determined using IR thermal imaging technique. If the materials fails at this number of cycle $\left(n_{\text {cycle }}\right)$, then the optimized fiber percentage towards predicting fatigue life will be proposed. If the materials do not fail at this cycle $(n$ cycle), then the fatigue test is continued by increase the number of cycle $(n+1$ cycle). The process will be continued until the materials fail.

\section{Results and Discussion}

\subsection{Determination of Defects and Fatigue Damage}

The IR thermography results are presented with contours of contrasting colours. The IR thermography analyses of the Kenaf reinforced epoxy specimens show that the defects exhibit higher temperatures than the areas without flaws. As has been discussed by Aggelis et al. (2011), stated that defects or inhomogeneities which lie below the surface affect the heat transfer rate when thermal energy is propagating into or out the structures [11]. IR thermal imaging has been provably determined fatigue damage; fatigue damage areas are increases with the number of cycles.

\subsection{Fatigue Tension Test}

Table 1. Stress (MPa) used in fatigue tests

\begin{tabular}{|c|c|}
\hline Specimens & Stress level from 0.9 to 0.4 UTS $(\mathrm{MPa})$ \\
\hline Pure epoxy & $29.58-13.15$ \\
\hline $45 \%$ to $55 \%$ kenaf/epoxy & $91.07-40.47$ \\
\hline $60 \%$ to $40 \%$ kenaf/epoxy & $116.26-51.67$ \\
\hline $75 \%$ to $25 \%$ kenaf/epoxy & $119.71-53.20$ \\
\hline
\end{tabular}

As listed in Table 1, 75\% fiber volume fraction Kenaf reinforced epoxy specimen has highest fatigue resistance as indicated by a highest range of stress level, 119.71-53.20 MPa followed by $60 \%$ Kenaf reinforced epoxy at 116.26-51.67 $\mathrm{MPa}$ and $45 \%$ Kenaf reinforced epoxy at 91.07-40.47 $\mathrm{MPa}$ then ultimately, the lowest fatigue resistance received by pure epoxy since the stress level range achieved was 29.58-13.15 MPa. From the curve fitting 
applied at the present data plots howver, the endurance limit characteristic has not been achieved since there is no drastic changes between the low cycle fatigue (LCF) and high cycle fatigue (HCF) behaviour from 1x100-1x106 cycle region as shown in Figure 3

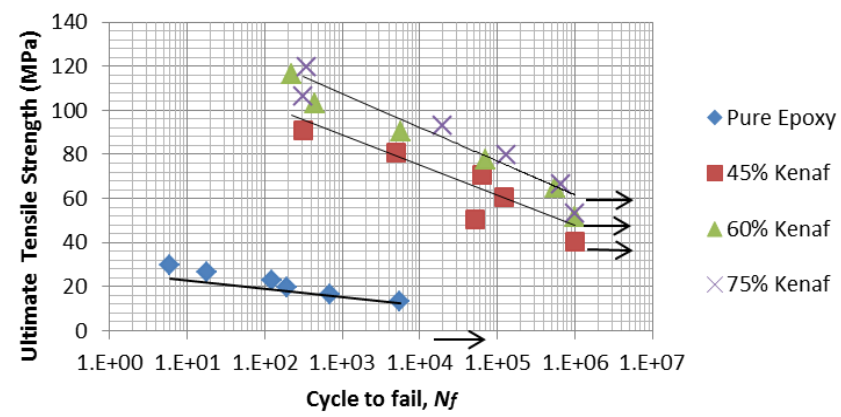

Figure 3. $S-N$ curve for pure epoxy and Kenaf reinforced epoxy composite at varied fiber loading of $45 \%, 60 \%$ and $75 \%$, respectively.

Comparison of the $S-N$ curves shape for Kenaf reinforced epoxy composite with a reference of glass reinforced epoxy composite published by Bathias (2006) [12] is shown in Figure 4 . The curve shapes of all composites were almost similar without concavity shape to meet endurance limit characteristic. This indicated that the fatigue life of Kenaf reinforced epoxy composites were comparable to glass reinforced epoxy composite.

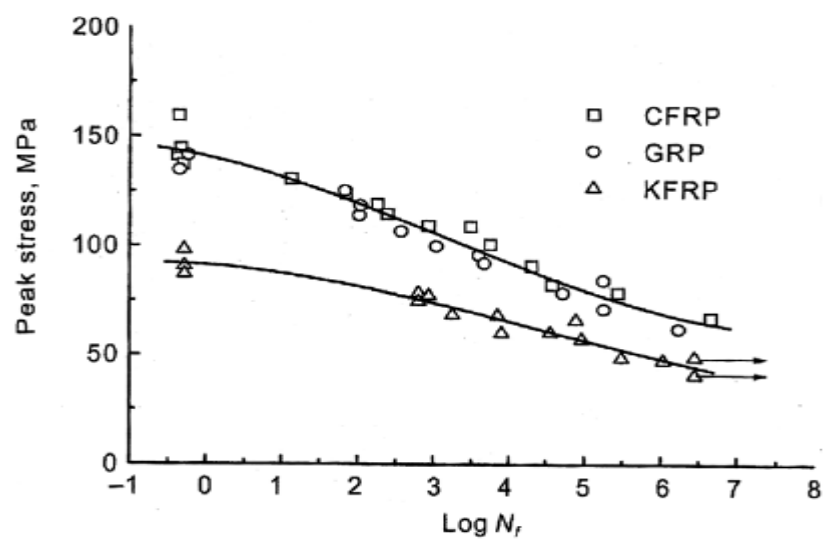

Figure 4. S-N curve for glass reinforced epoxy composite published by Bathias (2006) [4]

\subsection{Fatigue Life Model}

The $S$-IR fatigue life which is based on damage accumulation model has been proved as a significant predictor for fatigue life in Kenaf reinforced epoxy by thermal imaging technique limited on certain parameters. It has been proved to be able to detect the surface imperfections, without include the consideration on other failure modes that occurred in the composite materials such fibre/matrix interface adhesion and delamination.



Figure 5. Estimation $S-N$ curve of Kenaf reinforced epoxy composites 
From $S-N$ curve as shown in Figure 5, the proposed function is represented by Equation (1);

$$
n_{\text {cycle }} \alpha 1 / \sigma_{\max }
$$

where $n$ is defined as a number of cycle $\left(n_{\text {cycle }}\right)$ and $\sigma_{\max }$ is stress maximum at $n$ cycle. Area of damage is defined as an area that shows a crack at failure cycle. Observation via IR thermal imaging shows the area of damage appeared in red colour. It also proposes another two functions as represented by Equation (2) and Equation (3):

$$
\begin{gathered}
\mathrm{n}_{\text {cycle }} \alpha \text { Area of damage, }\left(\mathrm{A}_{\mathrm{d}}\right) \\
\mathrm{n}_{\text {cycle }} \alpha \text { Temperature of area of damage }\left(\mathrm{T}_{\mathrm{d}}\right)
\end{gathered}
$$

Figure 6 shows thermography for $45 \%$ Kenaf reinforced epoxy composites at point $\mathrm{A} 3$ to $\mathrm{A} 5$ respectively;

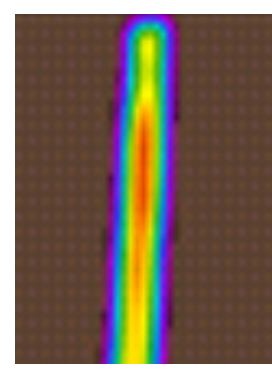

(A3)

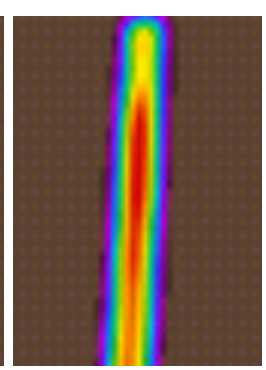

(A4)



(A5)
Figure 6. Thermography of fatigue damage accumulation for $45 \%$ kenaf epoxy composites at point $\mathrm{A} 3$ to $\mathrm{A} 5$

Figure 7 shows thermography $60 \%$ Kenaf reinforced epoxy composites at point B3 to B5 respectively;

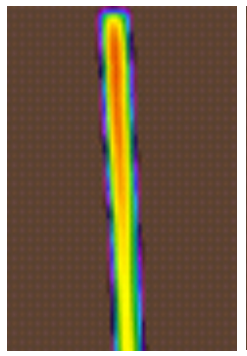

(B3)

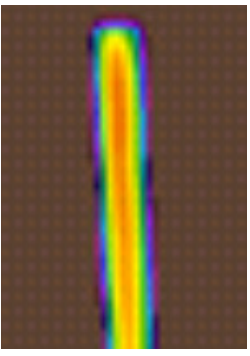

(B4)

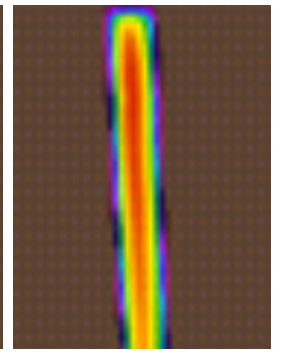

(B5)
Figure 7. Thermography of fatigue damage accumulation for $60 \%$ Kenaf reinforced epoxy composites at point B3 to B5
Figure 8 shows thermography 75\% Kenaf reinforced epoxy composites at point $\mathrm{C} 3$ to $\mathrm{C} 5$ respectively;

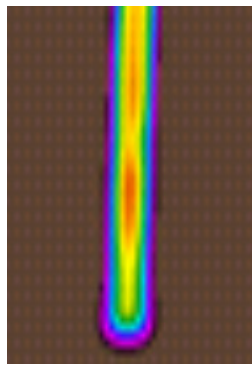

(C3)

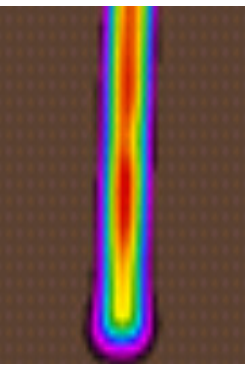

(C4)

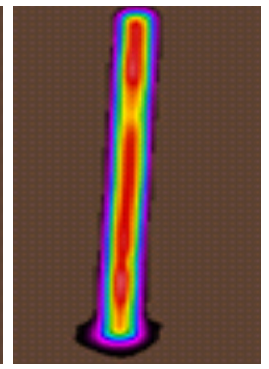

(C5)
Figure 8. Thermography of fatigue damage accumulation for $75 \%$ Kenaf reinforced epoxy composites at point $\mathrm{C} 3$ to $\mathrm{C} 5$

The higher stress level, the lower is the fatigue life as presented by Equation (1). The relation of fatigue life, $N$ and temperature of area damages $T_{d}$ is given in Equation (2). Area of damage, $A_{d}$ is determined as the hottest area which appears in red and records the highest temperature on the surface. As claimed by Choi et al., (2008) thermal imaging technique or thermography is a surface thermal radiation measurement technique that is used to detect spatial variations in the measured surface temperature pattern [13]. The hottest area defined as the faulty area which contained much defects and presented in contour colour of yellow, orange and red. This area recorded the highest temperature on the specimen surface. As observed from Figure 6 to 8 , it is found that area of damages, $A_{d}$ for all specimens increased linearly with the increased number of cycle, $n_{\text {cycle }}$, as written in Equation (3). It is also observed that the increased area of damages has reciprocally increased the temperature on the specimens' surface. The relation between area of damages and temperature, $T_{d}$ is visualized in Equation (4).

Area of damages, $\left(A_{d}\right) \alpha$ Temperature of damages area $\left(T_{d}\right)$

Areas of damages are represented by red colour which indicates the highest temperature, as in Figure 6 to Figure 8. Area of damages is measured by using square mesh. The size of each square is $0.5 \mathrm{~mm} \times 0.5 \mathrm{~mm}$. The relation between the stress of the material with the area of damages $\left(A_{d}\right)$, number of cycle $\left(n_{\text {cycle }}\right)$ and temperature $\left(T_{d}\right)$ on the surface defects is illustrated via a Venn diagram below: 


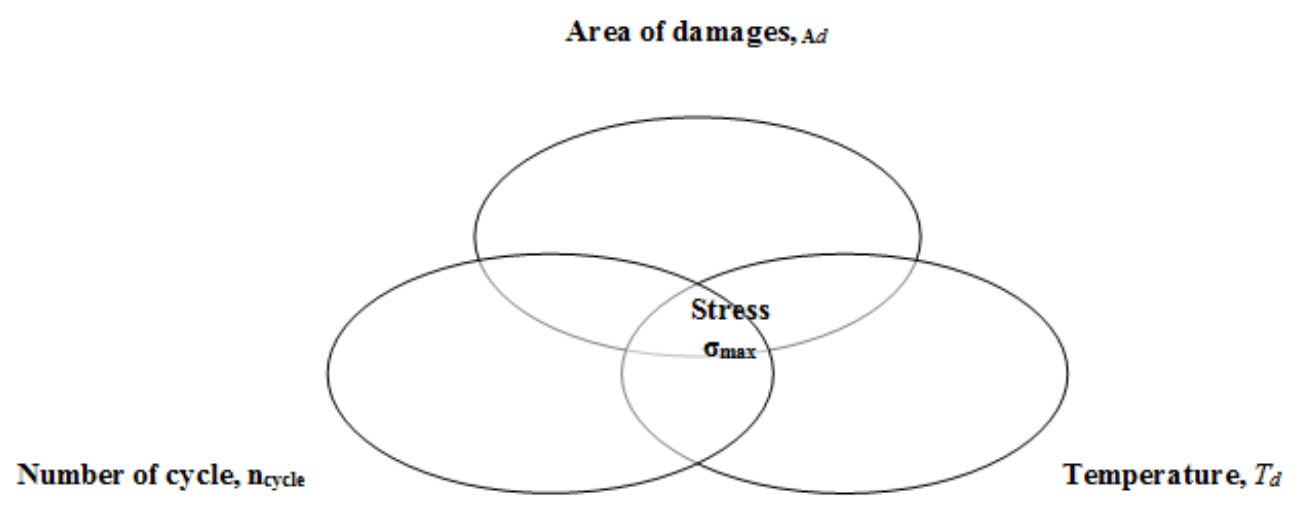

Figure 9. Venn diagram presents the relationship of stress with area of damages, number of cycle and temperature

In this study, the parameters used are stress $(\sigma)$, area of damage $\left(A_{d}\right)$ and temperature of the specimens $\left(T_{d}\right)$ after fatigue failure. It can be written as Equation (5) below;

$$
N_{f}=f\left(\sigma, A_{d}, T\right)
$$

Then to estimate fatigue life, Equation (5) can be written as Equation (6)

$$
N_{\text {fpredicted }}=\sum_{n=1}^{n=6} K_{n}\left\{\sigma_{n}, T_{n}\right\}
$$

Where; $K$ represents $A_{d}$,

\begin{tabular}{|c|l|}
\hline $\mathrm{n}$ & $=$ number of specimen \\
\hline$K_{n}=A_{d}$ & $\begin{array}{l}=\text { intensity factor for composites } \\
=\text { area of damage }\end{array}$ \\
\hline$\sigma_{n}$ & $=$ Stress of specimen \\
\hline$T_{d n}$ & $=$ Temperature of specimen \\
\hline
\end{tabular}

So, it states that;

$$
\mathrm{N}_{\text {fpredicted }}=\mathrm{N}_{\text {fexperimental }}
$$

Therefore;

$$
\begin{gathered}
N_{\text {fpredicted }}=\sum_{n=1}^{n=6} K_{n}\left\{\sigma_{n}, T_{n}\right\} \\
=\sum_{n=1} K_{1}\left\{\sigma_{1}, T_{1}\right\}, \sum_{n=2} K_{2}\left\{\sigma_{2}, T_{2}\right\}, \sum_{n=3} K_{3}\left\{\sigma_{3}, T_{3}\right\}, \\
\sum_{n=4} K_{4}\left\{\sigma_{4}, T_{4}\right\}, \sum_{n=5} K_{5}\left\{\sigma_{5}, T_{5}\right\}, \sum_{n=6} K_{6}\left\{\sigma_{6}, T_{6}\right\}
\end{gathered}
$$

In this study, the proposed S-IR model which has been developed based on the determination of area of damage $\left(A_{d}\right)$ by IR thermal imaging technique has been proven successful in estimating the fatigue life of kenaf reinforced epoxy composites.

Table 2 to Table 4 show comparison of results for fatigue life between the experimental procedure and the prediction method via $S$-IR model (as already given in Equation 5). To further illustrate the difference between these two methods, Figure 10 to Figure 12 is presented. Noteworthy, Figure 10 shows the predicting curve is slightly lower than experimental data with 3.5 percent different. While Figure 11 shows the predicting curve is slightly lower than experimental data with 2.2 percent different. In Figure 12, it is clear that the predicting curve is slightly higher than experimental data with 15 percent different. In addition, the results for specimen of $75 \%$ kenaf epoxy composites has a different trend compared to specimen of $45 \%$ Kenaf reinforced epoxy composites and specimen of 60 Kenaf reinforced epoxy composites. This happened due to defect-laden in the specimen of $75 \%$ Kenaf reinforced epoxy composites. The area of damage for this specimen is recorded, which includes the defects or imperfections on the specimens' surface.

Table 2. Fatigue life estimation using $S$ - $I R$ model for $45 \%$ Kenaf reinforced epoxy composites

\begin{tabular}{|c|c|c|c|c|c|}
\hline $\begin{array}{c}\text { Number of } \\
\text { specimens, } \mathrm{n}\end{array}$ & $\begin{array}{c}\text { Stress, } \sigma \\
(\mathrm{MPa})\end{array}$ & $\begin{array}{c}\text { Area of damage, } \\
A d\left(\mathrm{~cm}^{2}\right)\end{array}$ & $\begin{array}{c}\text { Temperature, } T_{d} \\
(\mathrm{~K})\end{array}$ & $\begin{array}{c}N_{f} \\
\text { (Predicted) }\end{array}$ & $\begin{array}{c}N_{f} \\
\text { (Experimental) }\end{array}$ \\
\hline 1 & 91.07 & 0.06 & 318.7 & 284 & 412 \\
\hline 2 & 80.95 & 1.25 & 327.3 & 33088 & 56998 \\
\hline 3 & 70.83 & 3.50 & 348.1 & 86270 & 78400 \\
\hline 4 & 60.71 & 4.25 & 353.3 & 77387 & 885807 \\
\hline 5 & 50.59 & 8.75 & 363.8 & 145327 & 150096 \\
\hline 6 & 40.48 & 16.50 & 368.2 & 251404 & 851766 \\
\hline
\end{tabular}




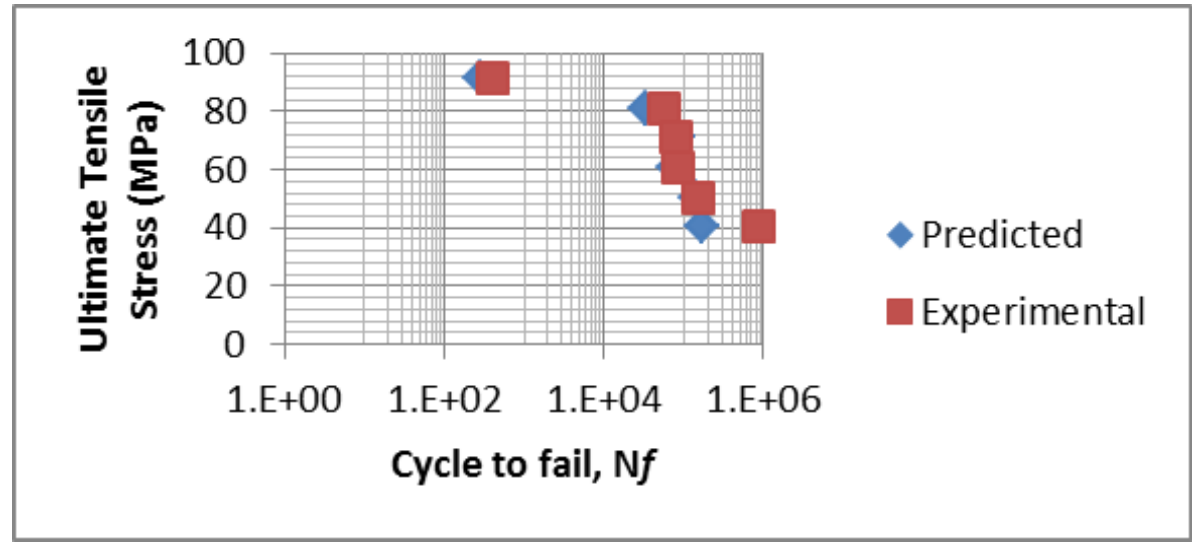

Figure 10. Comparison of experimental data with predicted $S$ - $I R$ model for fatigue life $45 \%$ Kenaf reinforced epoxy composites

Table 3. Fatigue life estimation using $S$ - $I R$ model for $60 \%$ Kenaf reinforced epoxy composites

\begin{tabular}{|c|c|c|c|c|c|}
\hline $\begin{array}{c}\text { Number of } \\
\text { specimens, } \mathrm{n}\end{array}$ & $\begin{array}{c}\text { Stress, } \sigma \\
(\mathrm{MPa})\end{array}$ & $\begin{array}{c}\text { Area of damage, } \\
A d\left(\mathrm{~cm}^{2}\right)\end{array}$ & $\begin{array}{c}\text { Temperature, } T_{d} \\
(\mathrm{~K})\end{array}$ & $\begin{array}{c}N_{f} \\
\text { (Predicted) }\end{array}$ & $\begin{array}{c}N_{f} \\
\text { (Experimental) }\end{array}$ \\
\hline 1 & 91.07 & 0.025 & 331.3 & 342 & 312 \\
\hline 2 & 80.95 & 1.75 & 338.4 & 47938 & 49000 \\
\hline 3 & 70.83 & 2.50 & 343.2 & 60772 & 62773 \\
\hline 4 & 60.71 & 5.75 & 360.6 & 125879 & 122990 \\
\hline 5 & 50.59 & 8.25 & 363.5 & 151713 & 51004 \\
\hline 6 & 40.48 & 12.5 & 365.0 & 186150 & 980056 \\
\hline
\end{tabular}

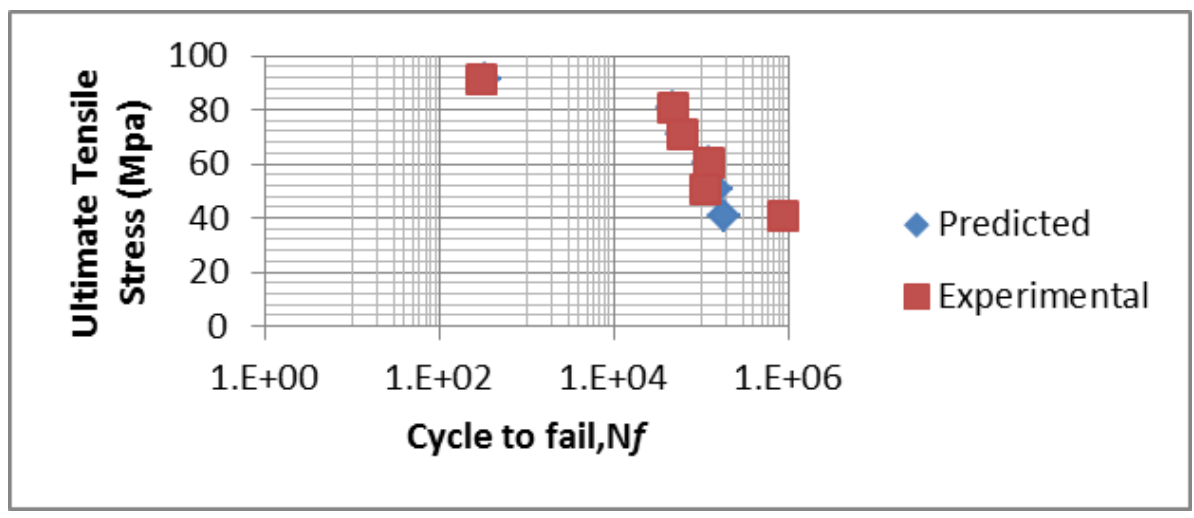

Figure 11. Comparison of experimental data with predicted $S-I R$ model for fatigue life $60 \%$ Kenaf reinforced epoxy composites

Table 4. Fatigue life estimation using $S$ - $I R$ model for $75 \%$ Kenaf reinforced epoxy composites

\begin{tabular}{|c|c|c|c|c|c|}
\hline $\begin{array}{c}\text { Number of } \\
\text { specimens, } \mathrm{n}\end{array}$ & $\begin{array}{c}\text { Stress, } \sigma \\
(\mathrm{MPa})\end{array}$ & $\begin{array}{c}\text { Area of damage, } \\
\operatorname{Ad}\left(\mathrm{cm}^{2}\right)\end{array}$ & $\begin{array}{c}\text { Temperature, } T_{d} \\
(\mathrm{~K})\end{array}$ & $\begin{array}{c}N_{f} \\
\text { Predicted })\end{array}$ & $\begin{array}{c}N_{f} \\
(\text { Experimental) }\end{array}$ \\
\hline 1 & 91.07 & 1.25 & 348.5 & 39672 & 256 \\
\hline 2 & 80.95 & 4.25 & 352.8 & 121376 & 22018 \\
\hline 3 & 70.83 & 8.75 & 363.3 & 225159 & 134523 \\
\hline 4 & 60.71 & 14.50 & 363.8 & 320251 & 569804 \\
\hline 5 & 50.59 & 15.75 & 368.2 & 293378 & 765321 \\
\hline 6 & 40.48 & 12.50 & 368.8 & 18661280 & 568878 \\
\hline
\end{tabular}




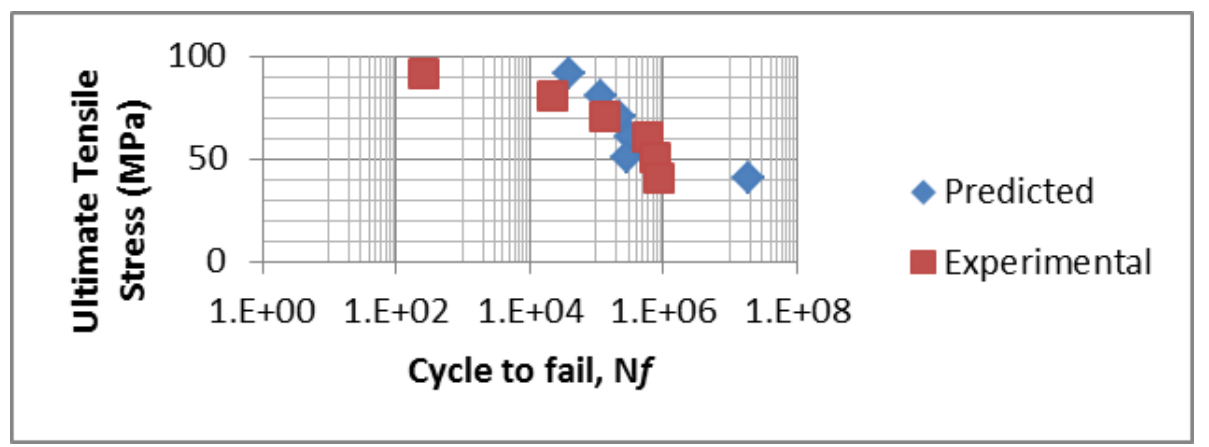

Figure 12. Comparison of experimental data with predicted $S$ - $I R$ model for fatigue life $75 \%$ Kenaf epoxy composites

As a conclusion, the estimation of fatigue life proposed by $S$-IR model are fixed with the result of fatigue life by experimental data for all specimens of $45 \%$ Kenaf reinforced epoxy composites, $60 \%$ Kenaf reinforced epoxy composites and specimen of $75 \%$ Kenaf reinforced epoxy composites. Based on the results, $S$-IR model also proposed that $60 \%$ Kenaf reinforced epoxy with thickness $0.3 \mathrm{~cm}$ is recommended as the best formulation to fabricate the specimens due to a longer fatigue life recorded. It has been proved to be able to detect the surface imperfections, without include the consideration on other failure modes that occurred in the composite materials such fiber/matrix interface adhesion and delamination. As advocated by Fatemi and Yang (1998) [14], although many damage models have been developed none of them, to date, is universally accepted. Each damage model can only be used for one or several phenomenological factors, such as load dependence, multiple damage stages, nonlinear damage evolution, load sequence and interaction effects, over load effects, small amplitude cycles below fatigue limit and mean stress. Regarding on the review by Suriani et al., [15] concluded that many fatigue analyses had been done in composites materials but studies carried out on composites materials reinforced by natural fibres are rather limited and also observed in the present results, most of the researchers obviously intended to use a non-destructive technique (NDT) in their work.

\section{Conclusions}

The observation indicates the damage areas recording the highest temperature and presenting with a red color. Predicting of fatigue damages modes also fixed with the predicting that have been done by using the types of defects for each specimens of kenaf reinforced epoxy composites. $S-I R$ model also proposed that $60 \%$ kenaf epoxy with thickness $0.3 \mathrm{~cm}$ is recommended as the best formulation to fabricate the specimens due to a longer fatigue life recorded. The result obtained from the fatigue cyclic tension test shows that $60 \%$ kenaf epoxy with thickness $0.3 \mathrm{~cm}$ had the highest fatigue resistance as indicated by a highest range of stress level, 119.71-53.20 MPa. Therefore, the $S-I R$ fatigue life which is based on damage accumulation model has been proved as a significant predictor for depicted fatigue life in kenaf reinforced epoxy by Infrared thermal imaging technique limited on certain parameters. Therefore the findings from the present study have contributed to the knowledge of fatigue life estimation and modeling of natural fiber reinforced composite materials.

\section{REFERENCES}

[1] Abdullah, A.H., Khalina, A., Aidy Ali. (2011). Effect of Fiber Volume Fraction on Unidirectional Kenaf/Epoxy Composites. Polymer-Plastic Technology and Engineering 50: (13) 186-187.

[2] Ku, H., Wang, H., Pattarachaiyakoop, N and Trada, M. (2011). A review on the tensile properties of natural fiber reinforced polymer composites. Composites Part B: Engineering, 42(4): 856-873.

[3] Nishino, T., Hirao, K., Kotera, M., Nakamae, K. and Inagaki, H. (2003). Kenaf reinforced biodegradable composite. Composite Sciences and Technology, 63: 1281-1286.

[4] Arib, R.M.N., Sapuan, S.M., Ahmad, M.M.H., Faridah, M.T. and Khairul Zaman, H.M.D. (2006). Mechanical properties of pineapple leaf fibre reinforced polypropylene composites. Materials and Design 27:341-348.

[5] Joseph, K., Filho, L.D.T., James, B., Thomas, S. and Carvalho, L.H. (1999) A review on sisal fibre reinforced polymer composites. Revista Braseilera de Engenharia Agricola Ambiental 3: 367-379.

[6] Gowda, T.M., Naidu, A.C.B and Chhya, R. (1999). Some mechanical properties of untreated jute fabric-reinforced polyester composites. Composites Part A: Applied Science and Manufacturing 30:227-284.

[7] Sreekala, M.S., Kumaran, M.G. and Thomas, S. (2002). Water sorption in oil palm fibre reinforced phenol formaldehyde composites. Composites Part A: Applied Science and Manufacturing, 33: 763-777.

[8] Abdul Khalill, H.P.S., Siti Alwani, M., Kamarudin, H. and Khairul, A. (2008). Chemical composition morphological characteristics and well structure of Malaysian oil palm fibers. Polymer-Plastics Technology and Engineering 47:1-8.

[9] M.J. Suriani, Aidy Ali, A. Khalina, S.M. Sapuan, S. Abdullah and Haftirman: Material Testing 54 (5) (2012), p340-346. 
[10] Giorleo, G. and Meola, C. (2002). Comparison between pulsed and modulated thermography in glass-epoxy laminates. NDT \& E International 35 (5): 287-292.

[11] Aggelis, D.G., Kordatos, E.Z., Strantza, M, Soulioti, D.V., and Matikas, T.E. (2011). NDT approaches for characterization of subsurface cracks in concrete. Construction and Building Materials 25:3089-3097.

[12] Bathias, C. (2006). An engineering point of view about fatigue of polymer matrix composite materials. International Journal of Fatigue 28(10): 1094-1099.
[13] Choi, M., Kang, K.., Park, J., Kim, W. and Kim, K (2008). Quantitative determinations of a subsurface defect of reference specimen by lock-in infrared thermography. NDT\&E International 41: 119-124.

[14] Fatemi, A. and Yang, J. (1998). Cumulative fatigue damage and life prediction theories: a survey of the state of the art for homogeneous materials. International Journal of Fatigue 20 (1): 9-34.

[15] M.J. Suriani, Aidy Ali, S.M. Sapuan, and A. Khalina. (2013). Aspect of Fatigue Analysis of Composite Materials: A Review. Pertanika J. Sci. \& Technol. 21 (1): 1 - 14. 